\title{
A MEMÓRIA, O CONTROLE DAS LEMBRANÇAS E A PESQUISA EM HISTÓRIA DA ENFERMAGEM
}

\author{
The memory, the control of remembrance and the research in history of nursing \\ La memoria, el control de los recuerdos y la investigación en historia de la enfermería
}

\author{
Tânia Cristina Franco Santos \\ Suely de Souza Baptista ${ }^{4}$
}

\author{
leda de Alencar Barreira² \\ Maria Angélica de Almeida Peres ${ }^{5}$
}

\author{
Maria da Luz Barbosa Gomes ${ }^{3}$ \\ Antonio José de Almeida Filho ${ }^{6}$
}

\section{RESUMO}

Estudo histórico-social. Objetivos: analisar a importância da memória no processo de construção da identidade profissional e discutir os principais desafios do pesquisador em história da enfermagem, relativos à preservação e divulgação da memória profissional. Fontes primárias: relatórios anuais de atividades da Escola de Enfermagem Anna Nery e o artigo "Memória e História para uma nova visão de enfermagem no Brasil”, de leda de Alencar Barreira. Fontes secundárias: literatura sobre memória e identidade profissional. Os dados, coletados de 1 de junho de 2009 a 30 de maio de 2010, foram classificados, organizados e analisados, de acordo com o método histórico. Resultados: a enfermagem brasileira, ao longo do século XX, utilizou símbolos e rituais como pontos de referência para evocar e sacralizar a memória da profissão e, assim, expressar e inculcar, intencional ou implicitamente, uma identidade de enfermeira. Conclusão: a simbiose entre memória e identidade profissional leva à necessidade de sua preservação.

Palavras- chave: Enfermagem. História da Enfermagem. Emblemas e Insígnias. Pesquisa em Enfermagem

\begin{abstract}
Social - historical study. Objectives: to analyze the importance of memory in the construction of professional identity and discuss the key challenges for research in nursing history, relating to the preservation and dissemination of professional memory. Primary data: annual reports of activities of the Anna Nery School of Nursing and the article "Memory and History for a new vision of Nursing in Brazil", by leda de Alencar Barreira. Secondary data: literature about memory and professional identity. The data, collected from June 1, 2009 to May 30, 2010, were classified, organized and analyzed according to the historical method. Results: the Brazilian nursing, throughout the twentieth century, used symbols and rituals as reference points to raise and sanctify the memory of the profession and thus express and impress, whether intentional or implicitly, an identity of nurse. We conclude that the symbiosis of memory and professional identity leads to the need for its preservation.
\end{abstract}

Keywords: Nursing. History of Nursing. Emblems and Insignia. Nursing Research

\section{Resumen}

Estudio histórico social. Objetivos: analizar la importancia de la memoria en el proceso de construcción de la identidad profesional y discutir los principales desafíos del investigador en historia de la enfermería, relativos a la preservación y divulgación de la memoria profesional. Fuentes primarias: informes anuales de actividades de la Escola de Enfermagem Anna Nery y el artículo "Memória e História para uma nova visão de enfermagem no Brasil", de leda de Alencar Barreira. Fuentes secundarias: literatura sobre memoria e identidad profesional. Los datos, recogidos de 01 de junio de 2009 a 30 de mayo de 2010, fueron clasificados, organizados y analizados, de acuerdo con el método histórico. Resultados: la enfermería brasileña, al largo del siglo XX, utilizó símbolos y rituales como puntos de referencia para evocar y sacralizar la memoria de la profesión y así, expresar e inculcar, intencional o implícitamente, una identidad de enfermera. Conclusión: la simbiosis entre memoria e identidad profesional lleva a la necesidad de su preservación.

Palabras clave: Enfermería. Historia de la Enfermería. Emblemas e Insignia. Investigación en Enfermería

\footnotetext{
'Pós-Doutora em História da Enfermagem. Escuela de Enfermería - Universidad de Valladolid. Professora Associada do Departamento de Enfermagem Fundamental da Escola de Enfermagem Anna Ney / UFRJ. Membro Fundador do Núcleo de Pesquisa de História da Enfermagem Brasileira. Bolsista de Produtividade em Pesquisa 2 / CNPq. Rio de Janeiro - RJ. Brasil. E-mail: taniacristinafsc@terra.com.br;'2Doutora em Enfermagem. Professora da Pós-Graduação da Escola de Enfermagem Anna Nery / UFRJ. Membro Fundador do Núcleo de Pesquisa de História da Enfermagem Brasileira. Pesquisadora do CNPq. Rio de Janeiro - RJ. Brasil. E-mail: iedabarreira@openlink.com.br; ${ }^{3}$ Doutora em Enfermagem. Professora Associada do Departamento de Enfermagem Fundamental da Escola de Enfermagem Anna Ney / UFRJ. Pesquisadora do Núcleo de Pesquisa de História da Enfermagem Brasileira. Rio de Janeiro - RJ. Brasil. E-mail: marialuz@alternex.com.br;ㅁoutora em Enfermagem. Professora da Pós-Graduação da Escola de Enfermagem Anna Nery / UFRJ. Membro Fundador do Núcleo de Pesquisa de História da Enfermagem Brasileira. Pesquisadora do CNPq. Rio de Janeiro - RJ. Brasil. E-mail: iedabarreira@openlink.com.br; ${ }^{5}$ Doutora em Enfermagem. Professora Adjunta do Departamento de Enfermagem Fundamental da Escola de Enfermagem Anna Ney / UFRJ. Pesquisadora do Núcleo de Pesquisa de História da Enfermagem Rio de Janeiro - RJ. Brasil. E-mail: aguaonda@uol.com.br;'Doutor em Enfermagem. Professor Adjunto do Departamento de Enfermagem Fundamental da Escola de Enfermagem Anna Ney / UFRJ. Pesquisador do Núcleo de Pesquisa de História da Enfermagem Brasileira. Rio de Janeiro - RJ. Brasil. E-mail: ajafilho@terra.com.br
} 


\section{CONSIDERAÇÕES INICIAIS}

0 presente estudo parte da premissa de que a memória, individual ou coletiva, é socialmente construída e representa um capital simbólico do indivíduo ou grupo ao patrimonializar, perpertuar e controlar as lembranças. Nesse sentido, os vestígios do passado, aqui concebidos como liturgias da memória, representam os grandes desafios para as pesquisas em história da enfermagem.

Pierre Nora, em clássico texto sobre memória e história, pontuou as especificidades conceituais desses termos, sendo a História uma reconstrução incompleta do que não existe mais, o que demanda a análise das continuidades temporais, das conjunturas e das relações entre as coisas. Já a memória como um fenômeno sempre atual e, por isso mesmo em permanente evolução, está aberta à dialética da lembrança e do esquecimento, inconsciente de suas deformações sucessivas, vulnerável a todos os usos e manipulações, susceptível de longas latências e repentinas revitalizações. ${ }^{1}$ Nesse sentido, um primeiro desafio para o trabalho historiográfico reside no entendimento de que o processo de reconstrução do passado está sujeito às sucessivas reinterpretações conforme as representações do presente e as idealizações do futuro.

Como fenômeno complexo, a memória comporta diferenciações, como se segue: a protomemória, que resulta em grande parte da interiorização dos hábitos e dos costumes; a memória propriamente dita, que é essencialmente da recordação ou reconhecimento, por convocação deliberada ou evocação involuntária (mas também feita de esquecimentos); e a metamemória, a que interessa mais aos historiadores, não porque exista independente das anteriores, mas porque define as representações que 0 indivíduo faz de sua memória e reconhecimento, expressando como cada um constrói sua identidade e sua distinção em relação aos outros, a partir do passado. ${ }^{2}$ Portanto, o conceito de metamemória como representação da memória individual ou coletiva remete ao entendimento de que "a memória é sempre uma construção feita no presente, a partir de vivências e experiências ocorridas em um passado sobre o qual se deseja refletir e entender. Enquanto construção, a memória está também sujeita às questões da subjetividade, seletividade e, sobretudo, às instâncias de poderes. Mesmo que reconstruída a partir dos indivíduos, a memória sempre nos remete a uma dimensão coletiva e social e, por extensão, institucional" 3:43

A propósito da ligação entre memória e poder, "a expressão coletiva da memória, ou melhor, da metamemória, não escapa à manipulação dos poderes mediante a seleção do que se recorda e do que consciente ou inconscientemente se silencia". $4: 59$ Essa seleção entre recordação e silêncio evidencia que a memória, embora na maioria das vezes esteja ligada a fenômenos de dominação, é objeto de contínua negociação porque está atrelada à seleção do que é essencial para construção da identidade do grupo.
Sobre esse aspecto, a memória coletiva, "além de uma conquista, é também um instrumento e objeto de poder, pois é vital para os grupos e as sociedades que lutam por reconhecimento" .5:88 Essa qualidade da memória leva à consciência da necessidade de sua preservação.

Para orientar o presente estudo, foram elaborados os seguintes objetivos: analisar a importância da memória no processo de construção da identidade profissional e discutir os principais desafios do pesquisador em história da enfermagem, relativos à preservação e divulgação da memória profissional.

\section{MÉTODO}

Estudo histórico-social que utilizou como fontes primárias, documentos escritos como relatórios anuais de atividades arquivados no Centro de Documentação da Escola de Enfermagem Anna Nery e o artigo intitulado "Memória e História para uma nova visão de enfermagem no Brasil, de autoria de leda de Alencar Barreira, publicado em 1999, na Revista LatinoAmericana de Enfermagem. Os critérios de seleção desses documentos foram orientados pela possibilidade de aprofundar a crítica a respeito das implicações entre memória e poder, através da ritualização das lembranças. A coleta de dados ocorreu no período de 1 de junho de 2009 a 30 de maio de 2010.

Os dados foram classificados, organizados e analisados, em conformidade com o método histórico, o qual preconiza três etapas essenciais: seleção de fontes primárias e secundárias; crítica dessas fontes e análise. A etapa de análise dos dados ocorreu de forma simultânea à coleta, em um processo de retroalimentação constante. As fontes secundárias contribuíram para a discussão dos dados e versaram sobre o tema memória e identidade profissional. Também se utilizou o conceito de habitus de Pierre Bourdieu - disposição incorporada que funciona como princípio gerador de práticas distintas e distintivas. ${ }^{6} \mathrm{~A}$ aplicação deste conceito se justifica pelo entendimento do conceito de habitus como uma forma de memória porque a produção e reprodução de lembranças comuns, bem como os esquecimentos resultam de disposições incorporadas, ou seja, impulsos para adotar comportamentos como aceitáveis ou adequados a responder as contingências da realidade social.

Nesse sentido, o processo historiográfico requer o conhecimento dos interesses do presente que norteiam a ação de lembrar e esquecer, pois as formas de concepção do passado são formas de ação que resultam de um sistema de incorporação de disposições, ou seja, um habitus, já que "conceber o passado não é apenas selá-lo sob determinado significado, construir por ele uma interpretação; conceber o passado é também negociar e disputar significados de desencadear ações".7:33

Vale ressaltar que, em cumprimento da Resolução 196/96 do Conselho Nacional de Saúde, o presente deriva do projeto de pesqui-sa intitulado "A Enfermagem Brasileira e os regimes ditatoriais do século XX", aprovado pelo Comitê de Ética em Pesquisa da Escola de Enfermagem Anna Nery/ 
Hospital São Francisco de Assis, em 24 de março de 2009, Protocolo Nº 04/2009 e apoiado pelo Conselho Nacional de Desenvolvimento Científico e Tecnológico/CNPq.

\section{RESULTADOS E DISCUSSÃO}

\section{A necessidade social de uma consciência do passado}

A consciência do passado configura-se como um componente inevitável do presente dos grupos sociais e corresponde ao conhecimento de sua dinâmica social, de suas instituições, tradições, sistemas de valores, rituais e relações com os diferentes grupos e espaços sociais. ${ }^{8}$ Nesse sentido, 0 conhecimento de um passado comum é importante para a identificação e preservação dos diversos grupos sociais, levando os mesmos à coesão social e a uma comunidade simbólica de sentido partilhada.

Outro aspecto importante sobre a memória é que construímos as lembranças a partir de relações que envolvem lugares, tempos e pessoas, uma vez que as memórias individuais ou coletivas se fazem em algum lugar que lhes imprime uma referência. Por sua vez, os indivíduos e grupos nesses lugares estão em constante disputa pelo poder ${ }^{3}$ e é justamente essa disputa de poder que determina o que será lembrado ou esquecido.

Assim, os estudos históricos que contam com as relíquias do passado são imprescindíveis para a sobrevivência dos diferentes grupos sociais, uma vez que a experiência histórica de um grupo ou sociedade é a sua referência positiva, sua advertência tangível que lhe fornece os subsídios perante os projetos do presente, evitando uma operação às cegas ou através de tentativas. ${ }^{8}$

No que concerne a história da enfermagem brasileira, a importância dos estudos históricos não reside apenas na preservação de recordações do passado, mas, na interpretação desse passado como uma necessidade social, afirmando que "os estudos históricos interessam sobremaneira à enfermagem, pois a construção de uma memória coletiva é o que possibilita a tomada de consciência daquilo que somos realmente, enquanto produto histórico",5:90 além disso, ao se pensar em construir versões históricas sobre a enfermagem, estas dependem basicamente de vestígios deixados por pessoas em um tempo e lugar; ${ }^{9}$ portanto, o que está em jogo na memória é a construção e preservação da identidade profissional e, por extensão, institucional.

Nesse jogo, o qual determina o que será lembrado ou esquecido, como também a maneira de lembrar, utiliza-se o material fornecido pela história e os atores especializados (historiadores) para procederem ao controle da memória através da seleção de testemunhas autorizadas que produzem os discursos em torno de acontecimentos e de personagens. Os vestígios desse trabalho de enquadramento da memória são os objetos materiais (monumentos, museus, bibliotecas) que guardam a memória e que permitem a integração de um momento histórico no presente dos indivíduos ou grupos, mediante a visualização de tais vestígios que funcionam como pontos de referências para a perpetuação da memória. ${ }^{10}$

No caso da memória da enfermagem brasileira, ao longo do século XX, foram utilizados diversos instrumentos de simbolização e de eternização como pontos de referência para evocar e sacralizar a memória da profissão e, assim, expressar e inculcar, intencional ou implicitamente, uma identidade de enfermeira. Assim, tem-se como exemplo, a lâmpada que evoca Florence Nightingale em cerimônias acadêmicas de escolas de enfermagem, a qual celebra e transmite para a posteridade a história de uma personalidade da enfermagem mundial que deve ser conhecida, aprendida e relembrada.

Além disso, as escolas de enfermagem criadas ao longo do século XX, por meio de suas fachadas, frequentemente solenes, indicavam aos transeuntes sua distinção em relação aos demais prédios dos bairros em que estavam localizadas. Seus espaços internos tinham também uma organização plena de significados: seus corredores e salas, as capelas, as bandeiras, os retratos das autoridades, os quadros de formaturas ou os bustos afirmavam saberes e apontavam modelos a serem seguidos. ${ }^{11}$ Nos dias atuais, os traços desse passado, presentes em tais construções arquitetônicas transcendem o seu significado material, pois vinculam as gerações do presente àquelas que as precederam, contribuindo para a formação de uma identidade compartilhada.

Também a institucionalização de emblemas e rituais da profissão foi uma das estratégias utilizadas pelas escolas de enfermagem, para proceder à seleção e atualização de lembranças dignas de serem apreendidas e transmitidas às futuras enfermeiras. Assim, tomando como exemplo as cerimônias de imposição de insígnias e de colações de grau, as inaugurações de monumentos alusivos à enfermagem (estátuas e bustos), além da inauguração de retratos de personagens ilustres da história da saúde do Brasil, como o do sanitarista Carlos Chagas, em 1925, como parte das comemorações da formatura da primeira turma de enfermeiras da Escola de Enfermagem Anna Nery, ${ }^{12}$ percebese que a ritualização de lembranças contribuiu para a incorporação de um habitus de enfermeira, compatível com as forças em jogo na sociedade.

Nesse processo de tradição inventada, a memória é sacralizada e convertida em um bem simbólico do grupo que, transmitido como herança através de celebrações; de inaugurações de bustos e retratos: ${ }^{13}$ e da identificação de monumentos nos espaços públicos, contribuiu para reforçar o sentimento de unidade do grupo de enfermeiras e, por conseguinte, um sentimento de filiação estatutária.

Além disso, as chamadas condiç̃̃es litúrgicas, ou seja, as prescrições que regem as formas de manifestações das autoridades, com as etiquetas das cerimônias e 0 ordenamento dos rituais ${ }^{14}$ constituem o elemento visível de um sistema de condições que visam à institucionalização de elementos 
identificadores da profissão, evidenciando a simbiose entre poder, memória, esquecimento e identidade.

Nesse processo, os monumentos, museus, bibliotecas, catedrais, teatros e edifícios, considerados instituições de memória, ao longo dos séculos XIX e também do XX, contribuíram para a perpetuação do discurso do poder, embora tenham sido permanentemente mostrados como espaço de construção e de conservação da memória de todos os grupos. ${ }^{15}$

Portanto, a memória coletiva, imposta e defendida mediante um trabalho especializado de enquadramento, é perpetuada através dos diversos documentos produzidos de acordo com as relações de poder então existentes expressadas, tanto nos documentos oficiais que, em geral, contam a história dos vencedores da história, quanto nos silêncios ou lacunas desses documentos. ${ }^{5}$

Não obstante, o trabalho de enquadramento da memória que celebra a memória do poder contribuiu para a constituição de espaços para conservação e guarda de documentos e de coleções personalistas e etnocêntricas, ainda que tratadas como se fossem a expressão da verdade das coisas. ${ }^{15}$

Tais espaços contribuem para a preservação da memória, uma vez que a "memória desempenha sua função social através de liturgias próprias, calcadas em lembranças provocadas por vestígios do passado". ${ }^{15: 8}$ Portanto, as lembranças, enquanto conteúdos da memória, estão intimamente relacionadas com os seus campos de objetivação e de transmissão, os quais são representados por imagens, monumentos, lugares, documentos diversos e, ainda, nos rituais que institucionalizam essas lembranças. ${ }^{4}$

No que concerne à memória da enfermagem brasileira, as lembranças comuns e as repetições ritualísticas, como, por exemplo, inaugurações, imposição de insígnias, cerimônias de colação de grau e etc., conjugadas com a conservação e transmissão de saberes e emblemas da profissão (bandeiras, estátuas, medalhas, hinos, personagens prestigiosas da história do Brasil e da enfermagem) são fatores fundamentais para a construção da identidade profissional.

Nesse contexto, a documentação histórica representada não somente pelos documentos oficiais, mas também pelos depoimentos orais, diários pessoais, álbuns de fotografias, etc., "que forma o complexo de conhecimentos não institucionais e representa a consciência coletiva dos grupos, contrapondo-se a um conhecimento formal que apoia os interesses de grupos constituídos", 5:88 conserva e transmite o sentimento de pertença do grupo.

Sendo assim, se a memória é uma construção social, os documentos, enquanto matérias-primas do trabalho historiográfico também o são; portanto, a produção do conhecimento também está sujeita "às injunções que condicionam o trabalho dos historiadores, homens e mulheres de seu tempo e que falam de um determinado lugar social, com determinada visão de mundo". $5: 89$ Esse trabalho exige erudição e sensibilidade no tratamento das fontes documentais, para que possa construir uma versão histórica consistente e convincente.

\section{As liturgias da memória e os desafios do pesquisador}

No bojo da Primeira Guerra Mundial, eventos como a Revolução de 1917 e o movimento operário demandaram a necessidade de os historiadores enfatizarem as transformações e os conflitos sociais. Nesse contexto, Lucien Febvre e Marc Bloch fundaram, em 1929, a revista Annales d'histoire économique et sociale (em 1945, Annales. Économies, Sociétés, Civilisation; a partir de 1991, Annales. Histoire-Sciences Sociales). Febvre e Bloch defendiam o caráter particular das Ciências Humanas, as quais não podiam ser regidas por leis. Contestavam a prática historiográfica dominante relativa ao enfoque político-diplomático e militar. ${ }^{8}$

Nesse contexto, na historiografia da enfermagem brasileira se faz necessário considerar que os diversos momentos da vida do país resultaram do jogo de forças políticas, econômicas e ideológicas, uma vez que a enfermagem, enquanto prática social, é condicionada pelo contexto em que atua, em que também exerce influência na sociedade em que se insere, segundo as forças sociais no campo da saúde. ${ }^{5}$

Dessa forma, um dos desafios do trabalho historiográfico é a contextualização dos documentos coletados, os quais devem ser concebidos como monumento-documento. Essa ideia se baseia no entendimento de que o monumento é construído intencionalmente para perpetuar uma recordação e, sendo assim, a concepção de documento-monumento traz a ideia de intencionalidade para o documento cuja produção resulta do jogo de forças que condicionou sua produção e reprodução. ${ }^{16}$

Assim, a preservação dos vestígios do passado é oportuna, pois a sensação de impossibilidade de preservar e avaliar a soma incomensurável de informações de diversas fontes, determinadas principalmente pelo avanço da informática, parece vir causando "o medo de uma amnésia coletiva". 5:88 Não obstante, essa gama de informações vem contribuindo para um maior interesse pelo estudo da história da enfermagem, em especial da relação entre memória e identidade profissional. Nesse contexto, o pesquisador depara com desafios tanto no impacto do avanço tecnológico na preservação da memória do tempo presente como na produção do trabalho historiográfico com fontes derivadas dos recursos tecnológicos vigentes, principalmente os de informática.

Os pesquisadores também enfrentam desafios relativos à busca de fontes históricas, pois, de um modo geral, os arquivos brasileiros enfrentam problemas relativos à insuficiência de recursos humanos, falta de equipamentos e instalações inadequadas, os quais concorrem para a deterioração dos documentos e para a pesquisa de tais documentos em condições insalubres Além disso, o pesquisador depara com dificuldades inerentes a ausência de um profissional especializado ou 


\section{Memória,lembranças e a história da Enfermagem}

mesmo de um guia de fontes que favoreça a localização e seleção das fontes documentais. ${ }^{17}$ Nesse sentido, tanto a perda de documentos pela guarda inadequada como a dificuldade em localizá-los prejudicam sobremaneira o trabalho historiográfico.

Sobre esse aspecto concorda Barreira ao afirmar que o desenvolvimento da pesquisa em História da Enfermagem depende da existência e da qualidade das fontes documentais, enfatizando a necessidade de envidar esforços continuados no sentido de proteger a memória da profissão, mediante a recuperação, produção e preservação de fontes históricas, além da produção e divulgação de pesquisas em eventos científicos e publicação de artigos em periódicos indexados de grande circulação. ${ }^{5}$ Essa preocupação se evidencia hoje através de esforços continuados de inúmeras escolas de enfermagem brasileiras, no sentido de organizar acervos que garantam a recuperação, preservação e divulgação de documentos referentes à enfermagem.

Não obstante, um grande desafio que se apresenta para os pesquisadores de história da enfermagem é a localização e incorporação de coleções pessoais de enfermeiros aos acervos históricos de instituições de enfermagem, pois se estima a existência de importantes documentos históricos representados, principalmente por fotografias, diários, cartas e objetos tridimensionais como medalhas, broches, troféus, entre outros. ${ }^{17}$

Ainda no tocante as coleções pessoais, os desafios também se pautam no desenvolvimento de relações interpessoais que possibilitem a recuperação desse passado, sem prejuízos emocionais ao protagonista da memória, sacralizada nessas coleções. Também é importante que, em caso de incorporação de coleções pessoais aos acervos históricos, a mesma não seja desmembrada, pois dificultaria o contato do pesquisador com as referências para as lembranças que eram evocadas, em seu conjunto, pelo dono da coleção.

Ademais do desafio de preservar fontes históricas, produzidas ao longo do século XIX e também do século XX, ou, ainda, de produzir novas fontes a partir dos sujeitos que participaram direta ou indiretamente do tema em investigação pelo pesquisador, tem-se também a necessidade premente de discutir o uso e preservação de novas fontes documentais derivadas de imagens e de sons obtidos diretamente da realidade, seja pela ficção ou pelo próprio registro documental. ${ }^{17}$

No que concerne ao uso de imagens, nos últimos dez anos, vem-se aumentando o uso de fotografias, como fontes históricas, em pesquisas sobre a história da enfermagem. No âmbito dessas pesquisas, os pesquisadores vêm utilizando fotografias pertencentes a arquivos históricos ou coleções pessoais, sendo a maioria em preto e branco, que, em geral, retratam eventos ocorridos na primeira metade do século XX. 0 potencial dessas imagens fotográficas para o trabalho de reconstrução histórica remete tanto à necessidade de preserválas como de resgatar informações a respeito delas, pois à medida que a fotografias se distanciam da época em que foram produzidas, mais difíceis são as possibilidades de recuperar informaç̃̃es sobre a composição fotográfica.

$\mathrm{Na}$ atualidade, a tecnologia digital multiplicou a presença social da fotografia e também revitalizou a discussão sobre a verdade das imagens fotográficas, devido à possibilidade de manipulação após a produção. ${ }^{17}$ No entanto, apesar das implicações da revolução digital, as quais devem demandar a discussão sobre a utilização e preservação dessas imagens, 0 desafio permanece o mesmo: a impossibilidade de analisar o texto fotográfico conforme uma perspectiva unívoca, uma vez que a produção de uma fotografia não é alheia a uma ação deliberada de enunciação textual, a um por em cena que deriva de uma ideologia que deve ser considerada na análise do texto fotográfico.

Vale ressaltar que, apesar dos avanços tecnológicos e da ampliação da noção de fonte histórica, o documento escrito continua importante para o trabalho historiográfico, pois nem mesmo a concepção, na atualidade, de que as fontes escritas também podem falsificar a verdade constitui impedimento para a preservação da memória. Sendo assim, a própria subjetividade do documento pode se constituir em objeto de estudo para o pesquisador e, paradoxalmente, evidenciar novas e convincentes versões históricas. Portanto, o desafio para o pesquisador, além da preservação dos documentos, consiste na reconstrução de uma versão sobre o passado, sempre tributária da interlocução com o documento.

Portanto, os diversos tipos de documentos bem como as instituições que abrigam a memória da enfermagem brasileira têm a função não apenas de certificar fisicamente a antiguidade e a continuidade, mas também de consagrar a identidade profissional. Sendo assim, os documentos precisam ser concebidos como herança material e simbólica, de modo a transmitir virtudes e competências, enfim, um habitus. Essa concepção demanda a necessidade de docentes e pesquisadores de história da enfermagem empreenderem estratégias para que os estudantes de enfermagem possam compreender a relação entre memória e identidade profissional, através da aquisição de um capital cultural que lhe possibilite a condição de herdeiro da memória da enfermagem brasileira.

Não obstante, não apenas o docente ou o pesquisador, mas também o enfermeiro que atua na assistência ou na administração deve estar atento aos documentos produzidos e arquivados em suas instituições, principalmente àqueles sob risco de deterioração, no sentido de conscientizar os responsáveis sobre o seu valor.

Vale ressaltar que o manuseio e a guarda adequada dos documentos determinam sua vida útil; portanto, a "difusão de uma filosofia de preservação da memória da enfermagem brasileira", ${ }^{18: 83}$ por certo, contribuirá para a incorporação de um habitus coerente com a compreensão da importância da preservação do passado para o entendimento da trajetória da identidade profissional na sociedade brasileira. 


\section{CONSIDERAÇÕES FINAIS}

A compreensão da sociedade enquanto construção histórica remete a necessidade de preservação da memória, pois ela é o fio condutor que liga as gerações umas às outras, dando um caráter de antiguidade, ubiquidade e continuidade. Nesse processo, o grupo tende a se dotar de meios que lhes permitam perpetuar-se para além da finitude dos agentes individuais ou até mesmo das instituições, através do efeito de simbolização e eternização conferido por: retratos ou estátuas que imortalizam a pessoa representada; edificações; escritos e também o dito e o silenciado, os quais transmitem para a posteridade a história digna de ser contada.

Nesse contexto, no que tange ao trabalho historiográfico, o pesquisador conta com uma multiplicidade de fontes documentais, cujo tratamento exige maior rigor metodológico e as quais devem ser analisadas não apenas na perspectiva do que revelam, mas também do modo como revelam os acontecimentos. Há ainda o desafio de preservar tanto os vestígios da memória, tanto os produzidos em tempos mais remotos como aqueles que, na atualidade, derivam de recursos tecnológicos em crescente e permanente evolução.

\section{REFERÊNCIAS}

1. Nora P. Entre memória e história: a problemática dos lugares. Projeto História, São Paulo, PUC. 1993 dez; 10 (1): 7-28.

\section{Candau J. Mémoire et identité. Paris: PUF; 1998.}

3.Oliveira AIB. História, memória e instituiç̃̃es: algumas reflexões teóricometodológicas para os trabalhos do Projeto Memória- SIBI/UFRJ. In: Oliveira AJB, organizador. Universidade e os lugares de memória. Rio de Janeiro: Fórum de Ciência e Cultura/Sistema de Bibliotecas e Informações/ UFRJ; 2008. p. 41-61.

4. Catroga F. Memória, história e historiografia. Coimbra: Quarteto; 2001.

5 Barreira IA. Memória e história para uma nova visão da enfermagem no Brasil. Rev Latino-am Enfermagem. 1999 jul; 7(3): 87-93.

6. Bourdieu P. Razões práticas. 8a ed. São Paulo: Papirus; 2007.

7. Alberti V. Ouvir contar: textos em história oral. Rio de Janeiro: CPDOC/ FGV; 2004.

8. Moradiellos E. El oficio de historiador. Madrid: Siglo XXI de España Ed; 2008.

9. Padilha MICS, Borenstein MS. História da enfermagem: ensino, pesquisa e interdisciplinaridade. Esc Anna Nery. 2006 dez; 10(3): 532-38.

10. Pollak M. Memória e identidade social. estudos históricos 1989; 2(3): 3-15.
11. Santos TCF. Significados dos emblemas e rituais na formação da identidade da enfermeira brasileira: uma reflexão após oitenta anos. Esc Anna Nery. 2004 abr; 8(1): 81-6.

12. Universidade Federal do Rio de Janeiro. Escola de Enfermagem Anna Nery. Relatório de atividades do ano de 1925. Rio de Janeiro; 1925.

13. Universidade Federal do Rio de Janeiro. Escola de Enfermagem Anna Nery. Relatório de atividades do ano de 1932. Rio de Janeiro; 1932.

14. Bourdieu P. A economia das trocas lingüísticas. 0 que falar quer dizer. $2^{a}$ ed. São Paulo: Edusp; 1998.

15. Ramos EHCL. Amemória, a história e as instituiç̧ões. Rev Humanidades. 2003 jan; 18(1): 5-8.

16.Le Goff J. Memória-história. In: Enciclopédia Einaudi. Verbetes "História", "Memória", "Documento/Monumento". Lisboa: Imprensa Nacional-Casa da Moeda; 1984.

17. Pinsky CB, Bacellar C, Grespan JCB, organizadoras. Fontes históricas. São Paulo: Ed Contexto; 2005.

18. Sauthier J, Carvalho MTC, Santos NMP. Centro de Documentação da Escola de Enfermagem Anna Nery-EEAN: uma contribuição à história da enfermagem. Rev Latino-am Enfermagem. 2000 out; 8(5): 81-4. 